\title{
O PROGRAMA RESIDÊNCIA PEDAGÓGICA: DIALÉTICA ENTRE A TEORIA E A PRÁTICA
}

\author{
J. H. L. MONTEIRO ${ }^{1}$, L. C. QUEIROZ ${ }^{2}$, A. L. B. ANVERSA ${ }^{3}$, V. F. M. SOUZA ${ }^{4}$ \\ Universidade Estadual de Maringá \\ Jlima_monteiro@hotmail.com ${ }^{1}$
}

Submetido 12/02/2020 - Aceito 26/02/2020

DOI: $10.15628 /$ holos.2020.9545

\begin{abstract}
RESUMO
A formação inicial docente tem sido pauta das discussões como cenário multifacetado com necessidades de uma interlocução centrada na realidade cultural, social e econômica da escola. Assim, no ano de 2018, na busca pela efetivação de uma práxis pedagógica com vistas a consolidar o processo formativo, o governo federal lançou o Programa de Residência Pedagógica (RP), com o intuito de aperfeiçoar a formação discente e fortalecer o vínculo entre IES e escola. Neste ano, o curso de licenciatura em Educação Física da Universidade Estadual de Maringá é contemplado com 24 bolsas direcionadas a acadêmicos, 3 professores preceptores e 1 orientador de área. Findada a experiência de 18 meses do edital, o presente trabalho objetivou analisar as contribuições do RP no processo formativo em Educação Física a partir dos
\end{abstract}

relatos dos residentes. Para tanto, sustentamo-nos na pesquisa do tipo qualitativo, de análise documental, cujo tratamento dos dados se deu a partir dos pressupostos da análise de conteúdo. As Categorias de intepretação emergidas foram: (a) as dificuldades encontradas pelos residentes; (b) facilidades da prática pedagógica para a implementação do RP pelos residentes; (c) percepção dos residentes quanto aos benefícios gerados pelo projeto. Os resultados indicaram um sentimento de satisfação por parte dos residentes durante a realização do projeto; e destacando as contribuições do Programa para a viabilização de uma práxis pedagógica formativa no contexto IES e escola, por meio da imersão dos futuros professores na realidade do ambiente educacional.

PALAVRAS-CHAVE: Residência Pedagógica, Educação Física, Docência, Formação de Professores.

\section{THE PEDAGOGICAL RESIDENCE PROGRAM: DIALECTICS BETWEEN THEORY AND PRACTICE}

\begin{abstract}
The initial teacher education has been the subject of discussions as a multifaceted scenario with the need for dialogue focused on the cultural, social and economic reality of the school. However, in 2018, in the search for the implementation of a pedagogical praxis with a view to consolidating the training process, the federal government launched the Pedagogical Residency Program (RP), with the aim of improving student training and strengthening the link between HEls and school. This year, the Physical Education degree course at the State University of Maringá is awarded 24 scholarships for academics, 3 teacher tutors and 1 area advisor. After 18month experience of the public notice, this study aimed to analyze the contributions of the RP in the formative process in Physical Education based on the residents'
\end{abstract}

reports. Therefore, we rely on qualitative research, based on document analysis, whose treatment of data was based on the assumptions of content analysis. The categories of interpretation that emerged were: (a) the difficulties encountered by residents; (b) facilities for teaching practice for the implementation of RP by residents; (c) residents' perception of the benefits generated by the project. The results indicated a feeling of satisfaction on the part of the residents during the realization of the project; and highlighting the contributions of the Program to the feasibility of a formative pedagogical praxis in the IES and school context, through the immersion of future teachers in the reality of the educational environment.

KEYWORDS: Pedagogical Residence, Physical Education, Teaching, Teacher training. 


\section{INTRODUÇÃO}

No cenário da educação brasileira na atualidade, frente às adequações às necessidades de interlocução latente entre Instituição de Ensino Superior (IES) e escola, e dos contextos que regem as políticas de formação docente no país, a preocupação com as condições de trabalho e a qualificação do processo de formação de professores têm se efetivado como uma demanda dos estudiosos da área. Segundo Gatti (2016) e Tavares, Santos e Santos (2020), tais preocupações inflam diante do crescente quadro de desigualdades socioculturais que nos permeiam.

Entende-se que o processo identitário de formação docente se dá pela relação estabelecida com os inúmeros momentos formativos do sujeito, quer sejam esses durante a formação inicial, anterior ou posterior a ela. Isto porque o processo de formação de um professor não é simples, é repleto de influências trazidas pela trajetória de vida do próprio sujeito. Para compor sua história, fazendo-se docente, é preciso "[...] um processo autorreflexivo da constituição de si mesmo, construído ao longo da vida, o qual tem como caraterísticas o dinamismo, o inacabamento, a incompletude e a mudança" (FLORES, 2018, p. 71). Existem alguns meios que inserem esse futuro professor, ainda no seu momento de formação inicial, no ambiente educacional, como, por exemplo, o estágio obrigatório realizado no decorrer da graduação, o qual auxilia o processo de aproximação com o campo de intervenção (SILVA JUNIOR, 2016; FLORES 2018; ANVERSA, 2017), as práticas como componentes curriculares e outras experiências originárias da tríade ensinopesquisa-extensão.

Com a realidade da implementação de uma nova estruturação da educação básica no cenário brasileiro, por meio da Base Nacional Comum Curricular, no ano de 2017, surgem outras demandas e necessidades na prática docente para a formação de professores. No ano de 2018, é lançado o edital para o Programa de Residência Pedagógica, objeto de estudo do presente artigo.

O Programa Residência Pedagógica - RP/UEM, viabilizado por meio da portaria GAB no 45, de 12 de março de 2018, edital no 06/2018 - CAPES, publicado em 29/05/2018, objetivou regulamentar a concessão de bolsas para discentes, chamados residentes, com matrícula ativa em cursos de licenciatura que tenham cursado, no mínimo, $50 \%$ da graduação. 0 curso de licenciatura em Educação Física da Universidade Estadual de Maringá - UEM passou a integrar as ações do Programa Residência Pedagógica por meio de seus editais 020/2018-PEN e 028/2018-PEN. Inicialmente, durante seu processo de seleção, o programa contou com 24 acadêmicos do curso de Educação Física - vinculados ao campus Sede, três professores preceptores e dois professores coordenadores da área, atuando em um Colégio da Rede Estadual da cidade de Maringá-PR.

De acordo com a Coordenação de Aperfeiçoamento de Pessoal de Nível Superior (CAPES), o programa compõe a Política Nacional e tem por princípio básico a compreensão de que os cursos de licenciatura devem assegurar aos seus egressos habilidades e competências que os permitam realizar um ensino de qualidade nas escolas da educação básica, durante seu processo de formação. O Programa conta com os seguintes objetivos:

Aperfeiçoar a formação dos discentes de cursos de licenciatura, por meio do desenvolvimento de projetos que fortaleçam o campo da prática e conduzam o licenciando a exercitar de forma ativa a relação entre teoria e prática profissional docente, utilizando coleta de dados e diagnóstico sobre o ensino e a aprendizagem escolar, entre outras didáticas e metodologias; Induzir a reformulação da formação prática nos cursos de licenciatura, tendo por base a experiência da residência pedagógica; Fortalecer, ampliar e consolidar a relação entre a IES e a escola, promovendo sinergia entre a 
entidade que forma e a que recebe o egresso da licenciatura e estimulando o protagonismo das redes de ensino na formação de professores; Promover a adequação dos currículos e propostas pedagógicas dos cursos de formação inicial de professores da educação básica às orientações da Base Nacional Comum Curricular (BNCC). (BRASIL, 2018)

Para que o processo de formação fosse objetivado, os residentes ficaram responsáveis por realizar seis atribuições no decorrer do programa, sendo elas: (a) elaborar seu plano de atividades em conjunto com docente orientador e preceptor; b) cumprir a carga horária mínima 440 horas de residência nos termos da Portaria38/2018; c) desenvolver as ações do plano de atividades com assiduidade e de forma acadêmica, profissional e ética; d) elaborar e entregar os relatórios previstos no prazo estabelecido no plano de atividade; e) participar das atividades de acompanhamento e avaliação do programa definidas pela Capes ou pela IES; f) comunicar qualquer irregularidade no andamento da residência ao seu docente orientador ou à coordenação institucional do Projeto na Instituição de Ensino Superior (IES).

O Programa Residência Pedagógica configura-se como um programa governamental relativamente recente, deste modo, são escassos os estudos que buscaram analisá-lo, em especial aqueles que investigam os impactos do programa na formação inicial dos futuros professores.

Machado e Castro (2019), em seu estudo, avaliam o Programa Residência Pedagógica como um ponto importante dentro do processo formativo de futuros professores e apontam que as experiências adquiridas no contexto de vivência escolar são os destaques do programa. Essa afirmação nos inquieta e nos leva a refletir sobre o tempo experimentado no "chão da escola" pelos futuros professores e a significância dessas ações na construção de sua identidade docente.

Segundo o que afirma os estudos de Pimenta (2017), Libâneo (2001) e Tardiff (2002), as experiências se tornam um processo contínuo de se identificar dentro da profissão para atuação na escola, o que também ajudará o professor a descobrir se a docência é realmente uma escolha acertada dentro dessa identificação.

As vivências práticas ao longo da formação inicial proporcionam a reinterpretação de saberes especializados de acordo com as experiências pessoais de cada indivíduo e ações não mediadas pelo processo formativo, contribuindo para construir e fortalecer a identidade profissional (PIMENTA \& LIMA, 2012). Tal identidade pode ser definida como uma categoria de pertencimento que engloba comportamentos, atitudes e opiniões vinculadas a uma determinada sociedade, sendo produto dos mecanismos de socialização primária e secundária do indivíduo (ANVERSA, 2017).

Silva et al. (2019) constatou que o Programa Residência Pedagógica proporciona um momento de contato não apenas com os alunos durante as regências, mas também com o professor da escola-campo, permitindo troca de vivências e articulação de conhecimentos. Evidencia-se que o RP se configura também, além de um suporte na formação inicial, como uma formação continuada para os professores preceptores, aqueles que acompanham os residentes em suas ações nas escolas. Assim, questionamos: quais as contribuições do RP no processo formativo dos residentes em Educação Física?

O Programa Residência Pedagógica tem se configurado como uma ação pedagógica significativa no processo de busca da efetivação na relação Universidade e Escola, por meio da integração e sistematização de uma estruturação curricular conjunta para o campo da Educação Física Escolar. Essas contribuições, segundo Zeichner (2010), surgem em razão de haver uma 
evidência significativa da falta de articulação entre a teoria conhecida em salas de aula e a realidade no interior das escolas, apontando para a desconexão entre os estudos teóricos e as suas utilizações no contexto prático dentro das escolas, nos cursos de licenciatura.

Dessa forma, o presente trabalho terá por objetivo analisar as contribuições do RP no processo formativo em Educação Física a partir dos relatos dos residentes.

\section{METODOLOGIA}

Para alcançarmos o objetivo, a presente investigação, de cunho qualitativo, adotou como procedimento metodológico a análise documental, utilizando-se da leitura e análise dos relatos de conclusão do Programa realizados pelos residentes, de modo a se ter uma melhor visão do problema proposto (Gil, 1991). Para tanto, sustentou-se nos pressupostos da análise de conteúdo sugerida por Minayo (1992), para a categorização empírica e analítica de textos.

A autora destaca que a categorização tem a função de interpretação, ou seja, atribuir significação ao que foi captado, buscando descobrir o que está implícito nos discursos, indo sempre além das aparências, de modo que, a partir das análises, seja possível eleger categorias a posteriori.

A coleta das informações se deu a partir dos relatórios de 21 residentes, individuais, e 3 relatórios coletivos, os quais foram escritos de forma coletiva, juntamente com os professores preceptores.

Construídos pelos residentes, os relatórios finais do Programa foram selecionados para análise pelo fato de que tais documentos objetivam esclarecer as aprendizagens e as dificuldades construídas no decorrer desse processo. Para Barreta (2008), relatórios finais caracterizam o encerramento de um processo, sendo importante instrumento de registro, análise e meditação, que corroboram para levantar "os pontos positivos e os pontos negativos ou frágeis da caminhada para propiciar um constante ir e vir entre teoria e prática” (BARRETA, 2008, p. 66).

Os relatórios finais contemplam o plano de atividades elaborado e executado pelos residentes e todas as ações realizadas no período de 18 meses nas quais participavam do Programa, além de uma dissertação intitulada "considerações finais", por meio da qual foram postas a visão geral acerca da participação de cada um dos residentes.

Salientamos que esta pesquisa é integrante do projeto institucional "Educação Física Escolar: perspectivas e ações pedagógicas na atualidade" e foi aprovada pelo Comitê de Ética e Pesquisa com Seres Humanos - UEM, por meio do parecer no 1.715.040/2016.

\section{RESULTADOS E DISCUSSÃO}

A interpretação dos relatórios perpassou pela perspectiva da conclusão dos pontos positivos e negativos descritos pelos residentes. Para melhor compreensão dos resultados, a partir da análise dos dados, podemos evidenciar três categorias de intepretação, sendo elas: (a) as dificuldades encontradas pelos residentes; (b) os fatos que facilitaram a prática pedagógica dos residentes; (c) a percepção dos residentes quanto aos benefícios gerados pelo projeto. 


\subsection{As dificuldades encontradas pelos residentes}

Nesta primeira categoria, analisaremos quais foram as dificuldades que os residentes tiveram durante o programa, e como conviveram ou encontraram formas de solucioná-las. Para Caimi (2008, p. 175), o momento em que o acadêmico adentra a escola é quando ele se depara com a realidade escolar e com as dificuldades do que é realmente ser um professor. Esse contato pode gerar tanto experiências positivas quanto negativas, que podem respingar em traumas e divergências futuras.

Podemos considerar que as maiores dificuldades relatadas por muitos residentes foram a qualidade dos materiais disponíveis para utilização durante as aulas de Educação Física e os espaços físicos da escola, mais especificamente os locais onde as aulas eram realizadas, que muitas vezes se mostravam insuficientes para uma aula prática satisfatória. Nesse sentido, podemos perceber no discurso dos residentes a insatisfação gerada quanto a essas situações, nos trechos abaixo:

"[...] Baixa qualidade dos materiais, as quais a demanda não atende a realização de atividades por várias turmas ao mesmo tempo." (Residente 01); "[...] em relação aos materiais a qualidade é baixa, não há materiais suficientes, e a demanda não atende todas as aulas, pois há várias turmas realizando as atividades ao mesmo tempo." (Residente 02); "[...] as dificuldades encontradas no período de regência foram: falta de materiais, falta de organização e respeito dos espaços disponíveis para o uso didático e resistência dos alunos ao se propor atividades novas." (Residente 10)

É notório que é um sentimento rotineiro de todos os professores a preocupação com os materiais e os ambientes onde suas aulas acontecerão, mas, para a Educação Física, os recursos materiais merecem uma atenção destacada diante das especificidades existentes (SEBASTIÃO \& FREIRE, 2009). Pois a Educação Física é uma disciplina que necessita de espaços que atendam às demandas físicas e materiais, que sejam, no mínimo, em quantidade ideal para todos os alunos.

Soler (2003) afirma que raramente as escolas públicas apresentam espaço e material adequados para as aulas de Educação Física, o que nos demonstra que este problema não afeta apenas os residentes, mas, infelizmente, se desenha como um problema em todo o país.

Anísio Teixeira já nos dizia: "Não há como fazer educação barata - como não se pode ganhar uma guerra barata. Se for nossa defesa que estamos construindo, o seu preço nunca será demasiado caro" (TEIXEIRA, 1971). O papel fundamental da escola não pode ser ceifado por falta de materiais ou espaço físico insuficiente para as aulas práticas.

Mas estes problemas não significam que o programa não tenha atingido seus objetivos, o que é claro nos relatos dos residentes, visto que a apropriação e a imersão na realidade escolar fazem parte do mundo concreto em que a classe de professores está inserida. Dessa forma, diante de todas as dificuldades também enfrentadas pelos professores, os residentes puderam experienciar a dificuldade e a capacidade adaptativa requerida pelos professores no ambiente escolar público:

"[...] Desde as dificuldades encontradas dentro da escola pela falta de material me proporcionou a curiosidade de materiais alternativos, novos métodos de preparar e executar a aula." (Residente 21). 
É uma prática comum dos professores de Educação Física, se verem obrigados a adaptarem suas aulas ou até mesmo os materiais disponíveis, para atingir o objetivo proposto. Para os residentes, a imersão nas atividades de adaptação e construção de materiais alternativos começou logo durante a formação inicial e já é possível perceber a complexidade da profissão docente no sentido de lidar com problemas e fazer deles, soluções.

Outro fator importante relatado pelos residentes, além da escassez de recursos físicos e falta de espaços adequados para as aulas, foi a relação humana para com os alunos. Segundo relatos, alguns alunos, em sua minoria, construíram certa resistência para a relação de respeito com os acadêmicos, como percebemos no relato:

"[...] quando a preceptora interferiu nas aulas, e os residentes ficavam com a sensação de impotência, principalmente em questões de broncas aos alunos, pedidos de silêncio; o aluno enxergar o residente "como um estagiário que não tinha muita autoridade". (Residente 01) [...] "houve momentos específicos onde sentimos que quando ela interferia nas aulas (preceptora), deixava os residentes com a sensação de perder autoridade". (Residente 02) "[...] por se tratar de uma idade aproximada entre os mesmos muitas vezes os alunos não obedeciam e alguns não realizavam as atividades planejadas pois não podíamos fazer nada contra eles." (Residente 03)

Para Nascimento e Silva (2019), a dificuldade encontrada para estabelecer um bom comportamento dos estagiários para com os alunos é normal. Acreditamos ser cultural a resistência estabelecida pelos alunos para com as atividades propostas pelos residentes, pelo fato de a disciplina ministrada ser Educação Física, e, em geral, este é o momento em que os alunos estão acostumados a ter uma "evasão da vida real" (sair da sala de aula) e realizar atividades livres.

Nesse sentido, Aquino (1996) aponta que a solução pode estar na forma como se dá a relação professor-aluno, ou seja, nos vínculos que se estabelecem nas relações cotidianas. Essa relação entre residente-aluno, conforme os relatos, era muitas vezes conturbada pela proximidade de idades entre ambos, o que gerava uma perca da imagem de autoridade aos residentes perante os alunos. Segundo estudos de Galinha e Francisco (2014), a falta de autoridade é um dos grandes motivos de estresse apontado pelos estagiários durante as regências de aulas.

Ainda analisando as dificuldades encontradas pelos residentes, conforme relatos, é possível perceber que os acadêmicos, com o frescor dos novos conhecimentos assimilados na universidade, apresentam-se com novas ideias e aulas diferentes e encontram resistência dos alunos no sentido de participação das aulas. Souza e Freire (2008) afirmam que muitas vezes as tentativas de mudanças apresentadas por professores esbarram na resistência dos alunos, habituados com aulas tradicionais.

Foi possível perceber diversos problemas e dificuldades enfrentadas pelos residentes e entender que, apesar das adversidades, a prática pedagógica vivenciada com afinco na escola, futuro campo de trabalho, reflete em aprendizados e experiências que, com certeza, ajudarão a moldar a identidade docente deste futuro professor.

\subsection{Fatos que facilitaram a prática pedagógica dos residentes}

Ainda na perspectiva da análise dos relatórios dos residentes, destacam-se, na segunda categoria, os fatos que facilitaram a prática pedagógica, a qual retrata o papel da mediação que o programa proporcionou aos acadêmicos durante as aulas regidas. Compreendemos que, para 
aplicar boas aulas, não se faz da noite para o dia. Muitos fatores influenciam no crescimento profissional dos estudantes-professores e fazem a mediação do aprender a ensinar.

Quando expresso nos relatórios fatos que auxiliaram e facilitaram a prática pedagógica, os residentes relataram:

[...] O trabalho em grupo foi positivo também principalmente pelo suporte na elaboração dos conteúdos desenvolvidos durante as aulas, com a contribuição e supervisão das professoras orientadoras e preceptoras, que deram todo o suporte de acolhimento e acompanhamento durante o projeto. (Residente 20), [...] disponibilidade da preceptora [...] foi possível desenvolver uma grande relação de professor/residente-aluno, onde sentimos que os alunos se sentiram mais próximos e a vontade durante todo o período que estivemos atuando no colégio. (Residente 11), [...] tivemos o total auxílio necessário que nos capacitou para a aplicação da regência da melhor forma possível. $A$ professora orientadora do projeto sempre esteve nos acompanhando ao longo do ano e dando total apoio e auxílio no que precisávamos, para que conseguíssemos cumprir com nossas obrigações $e$ deveres dentro do programa. Na escola sempre fui muito bem atendida pela comunidade de escolar e pela preceptora, que deu suporte suficiente e auxílio para as elaborações das aulas durante o ano, a transmissão de experiência da professora preceptora contribuiu auxiliando em questões como domínio de turma e controle de tempo das atividades durante as aulas. A troca de experiências com os outros residentes também foi muito válido e de extrema importância, reuniões semanais aconteciam e trocávamos ideias e experiencias já vivenciadas na escola para que adaptássemos as atividades. (Residente 04); [...] a preceptora sempre esteve disposta a nos responder quando solicitada e aberta para novos questionamentos. (Residente 02)

Percebe-se que os residentes salientaram como "fundamental" a relação de proximidade para com as preceptoras. Em geral, o fato de o programa ser produzido por um grupo de pessoas, incluindo professores de longa carreira, de acordo com os relatos, foi um, ou se não, o principal fator auxiliador para o bom desenvolvimento das aulas durante o projeto.

Acerca da coletividade em que os residentes e professores puderam vivenciar, Gandin (1994) diz que um processo mais justo e eficaz só se efetivará quando houver a participação e o protagonismo de todos os participantes, ou seja, a presença e o auxílio de ambos os lados se fez importante e conferiu benefícios para o processo.

A boa relação com os professores preceptores e a professora orientadora do projeto se demonstra importante, uma vez que foi destacada nos relatos dos residentes como um fator que conferia segurança em suas ações, pois estas lhes deram o suporte devido para amparar suas dúvidas e angústias em relação a preparo e regência das aulas.

\subsection{Percepção dos residentes quanto aos benefícios gerados pelo projeto}

$\mathrm{Na}$ terceira categoria, podemos fazer uma análise acerca da percepção dos residentes quanto aos benefícios gerados pelo projeto. Ilustramos, na figura 1 , os indicadores que retratam a relevância do programa para o processo de formação dos futuros professores participantes da RP. 


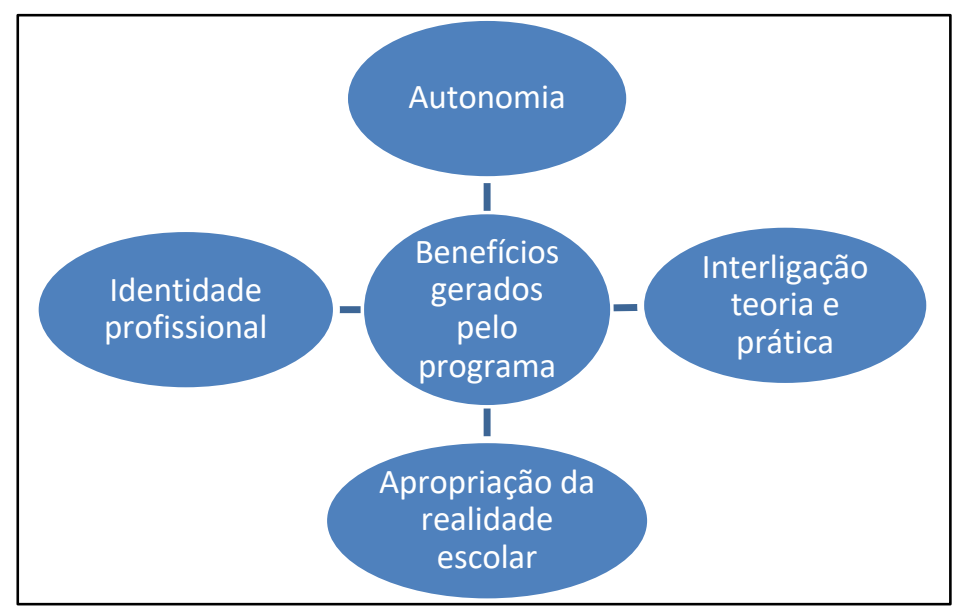

Figura 1: Percepção dos residentes em relação aos benefícios do Programa Residência Pedagógica.

Como um indicador a partir dos relatos de conclusão, evidenciou-se que as ações que incorporam as discussões durante o Programa de Residência Pedagógica apresentam o constante processo de formação para o exercício da profissão, fazendo uma interligação entre a teoria e a prática, conforme apontam trechos de relatos abaixo:

Na relação com o Residência Pedagógica... [...] ocorre uma melhora no ensino e aprendizagem, pois quando o acadêmico tem a teoria na faculdade ele percebe a importância de buscar novos conteúdos e se apropriar do mesmo, assim melhorando sua prática que ocorre na escola (Residente 02), [...] 0 programa em questão nos ajuda a complementar a nossa formação auxiliando na parte teórica $e$ implantando a prática no nosso cotidiano (Residente 03), [...] também contribuiu para que a teoria e a prática que vemos na graduação se efetivasse. Isso nos mostra que é possível uma parceria entre a Universidade e a educação básica, que elas podem e devem conversar para que haja um avanço no campo educacional (Residente 08), [...] Foi possível unir a teoria desenvolvida no ambiente da universidade e universaliza-la ao contexto do ambiente escolar na prática. Evidenciando assim a importância da união da universidade com a comunidade externa onde está inserida, elevando o grau de qualidade de ensino da educação (Residente 11), [...] A experiência com os conteúdos foi riquíssima, ainda mais por ainda estarmos vendo as teorias na universidade, e podendo aplicá-las na prática (Residente 17)

Para Fontana e Fávero (2013), a interligação entre a teoria e a prática constitui o processo de reflexão do trabalho educativo. Para as autoras, o professor reflexivo que alinha as duas ações demonstra contribuições e mudanças que essa reflexão produz na prática escolar. Para Moreira (2012, p. 2), a aprendizagem significativa acontece por meio da relação entre teoria e prática, sendo "[...] um processo por meio do qual uma nova informação relaciona-se com um aspecto relevante da estrutura de conhecimento do indivíduo". Dessa forma, a aprendizagem significativa se materializa quando a nova informação, advinda de uma nova apropriação teórica e se sustenta em conceitos preexistentes na estrutura cognitiva do sujeito.

Outro ponto levantado demonstra que a imersão dos residentes na escola os fez compreender e interagir com a realidade, conforme apontam depoimentos abaixo:

Pudemos experimentar com afinco o chão da escola e perceber todas as especificidades $e$ complexidades, chegando perto de uma rotina real de um professor (Residente 01),[...] com o Programa Residência Pedagógica vivenciamos a realidade da escola pública, fato que é de extrema importância para os acadêmicos em formação docente, levando em consideração que em muitas 
escolas há falta de materiais e um elevado número de alunos em uma sala (em sua maioria, desinteressados) (Residente 03), [...]com o projeto eu aprendi realmente como funciona a escola, como devo trabalhar nela, aprendi a planejar aulas, aplicar essas aulas tenho certeza que irei terminar o projeto com uma experiência enorme que eu não conseguiria adquirir somente nos meus estágios obrigatórios... (Residente 07)

Lima e Damasceno (2018, p. 282) apontam que esse contato dos residentes com a realidade escolar é benéfica para os bolsistas da Residência Pedagógica, visto o fato de que "[...] conhecendo de perto os anseios dos alunos e as complexidades da vida escolar, podemos nos preparar para exercer nossa futura profissão." Essa inserção para com a realidade fez com que os residentes relatassem que a experiência na prática os fez adquirir uma maior autonomia com relação a suas aulas.

Tivemos autonomia para elaboração, aplicação e correção de todo o processo avaliativo e na atribuição das notas (Residente 02), [...] ter esse contato direto com os alunos através da residência pedagógica nos possibilitou uma autonomia como professor para decidir a melhor forma de transmitir os conhecimentos produzidos historicamente sobre a cultura corporal através das práticas corporais (Residente 15), [...] durante a RP, tive um verdadeiro pertencimento como professor de turma, pois tinha uma autonomia durante as aulas, coisas que não havia acontecido durante $o$ estágio. Creio que a RP é de suma importância para a formação acadêmica dos licenciando fazendo com que ele tenha experiências mais profundas no meio escolar. (Residente 22)

Rocha e Pozzebon (2013) destacam que a autonomia no processo de formação docente é um dos princípios que o mundo atual requer, sendo uma característica essencial para o futuro profissional do professor, qual foi provocada e refletida durante o período do Programa Residência Pedagógica.

Matos, Nista-Piccolo e Borges (2016) destacam que a formação inicial em licenciatura, no geral, tem função importante no desenvolvimento da identidade docente dos acadêmicos. Para as autoras, neste momento "[...] os acadêmicos (re)conhecem no papel do professor os seus saberes, competências e habilidades" (p. 51).

Os residentes iniciaram a aplicação das aulas com visão de aluno, ao decorrer do processo, a visão foi modificada, passando a assumir a identidade de professor [...] foi possível estabelecer vínculos profissionais e pessoais que proporcionaram momentos de identidade profissional. A atuação da preceptora foi/será fonte de inspiração para nós, quando nos tornarmos professores efetivos (Residente 02), [...] a RP em síntese nos fornece algo que o estágio supervisionado jamais vai oferecer que é essa identidade profissional e esse pertencimento de responsabilidade que criamos durante esse tempo dentro do programa de RP, sem dúvidas há grandes diferenças entre os formandos que participaram da RP e os que só tiveram contato com o meio escolar por meio do estágio supervisionado (Residente 12)

Compreende-se que as relações humanas proporcionadas pelo Programa Residência Pedagógica se tornam fundamentais para o processo de desenvolvimento docente dos residentes. As experiências adquiridas na observação e na participação conjunta dos professores preceptores, na relação com os alunos e os próprios colegas residentes constituem um processo de identidade profissional dos acadêmicos, o que, segundo Dubar (2012), é permanente e se trata das relações existentes com outros e consigo inseridas em situações de trabalho. 


\section{CONSIDERAÇÕES FINAIS}

Com a análise apresentada acerca da realização do Programa Residência Pedagógica, por meio dos relatórios de conclusão do programa para o curso de Educação Física participante do referido edital, pode-se concluir que houve um sentimento de satisfação por parte dos residentes durante todo o processo de realização do projeto. Termos como "sentimento de pertencimento", "o programa contribuiu de forma significativa para a minha formação" e "estamos prontos para encarar a vida profissional" estavam presentes em diversos relatos. Mesmo mencionando as fragilidades e as dificuldades apresentadas na prática escolar, os residentes participantes deste edital do RP do referido curso consideraram que o programa contribuiu significativamente com a formação profissional quando comparado a uma experiência somente com o Estágio Obrigatório.

Assim, destaca-se que a participação dos acadêmicos em programas governamentais que envolvam a extensão da Universidade para o próprio campo de intervenção profissional dos estudantes proporciona aos futuros professores o conhecimento real do ambiente educacional, oferecendo, dessa forma, uma rica experiência no processo de formação dos futuros professores.

\section{REFERÊNCIAS}

Anversa, A. L. B. (2017). Estágio Curricular e a constituição da Identidade Profissional do bacharelem Educação Física. 2017. Tese de Doutorado, Programa de Pós Graduação em Educação Física, Centro de Ciências da Saúde, Universidade Estadual de Maringá. Maringá, Brasil.

Aquino, J. G. (1996). A desordem na relação professor-aluno: indisciplina, moralidade e conhecimento. In Indisciplina na escola: alternativas teóricas e práticas. São Paulo: Summus.

Barreta, R. Z. (2008). O estágio supervisionado na formação de professores em cursos de pedagogia. Dissertação de Mestrado, Programa de Pós Graduação em Educação, Universidade do Oeste de Santa Catarina. Joaçaba, Brasil.

Brasil. (2018). Edital Capes 06/2018. Disponível em https://www.capes.gov.br/images/stories/download/editais/01032018-Edital-6-2018. Acesso em 04 de fevereiro de 2020.

Caimi, F. E. (2008). Aprendendo a ser professor de História. Passo Fundo: Editora da Universidade de Passo Fundo.

Dubar, D. A. A. (2012). Construção de si pela atividade de trabalho: a socialização profissional. Cadernos de Pesquisa, 42(146), 351-367. Doi: 10.1590/S0100-15742012000200003.

Flores, P. P. (2018). O processo de identização docente durante o estágio curricular supervisionado: em jogo no campo da Educação Física. Tese de Doutorado, Programa de Pós Graduação em Educação Física, Departamento de Educação Física, Universidade Estadual de Maringá. Maringá, Brasil. 
Fontana, M. J.\& Fávero, A. A. (2013). Professor reflexivo: uma integração entre teoria e prática. Revista de Educação do IDEAU, 8(17), 1-15.

Galinha, S.\& Francisco, C. M. (2014). O stresse do aluno estagiário. EgitaniaSciencia, 47-60.

Gandin, D. (1994). Planejamento como Prática Educativa. São Paulo: Loyola.

Gatti, B. A. (2016). Formação de professores: condições e problemas atuais. Revista Internacional de Formação de Professores, 1(2), 161-171.

Gil, A. C. (1991). Como elaborar projetos de pesquisa. São Paulo: Atlas.

Libâneo, J. C. (2001). Organização e gestão da escola: teoria e prática. Goiânia: Alternativa.

Lima, L. G. S. C.\& Damasceno, T. T. S. (2018). Análise da realidade escolar como forma de direcionar ações do Programa Residência Pedagógica [Resumo]. In: Congresso Internacional de Política Educacional e Emancipação (Eds) As relações entre Estado, Sociedade e Educação, (p. 279). Fortaleza, Brasil.

Machado, L. V.\& Castro, A. (2019). Uma experiência do Programa Residência Pedagógica com a abordagem da teoria das inteligências múltiplas. Seminário de Integração e Socialização de Pesquisas e Práxis Pedagógica em Matemática, 1, 1-4.

Matos, T. S.\&Nista-Piccolo, V. L.\& Borges, M. C. (2016). Formação de professores de educação física: identidade profissional docente. Conhecimento \& Diversidade, 8(15), 47-59. Doi: 10.18316/2237-8049.2016.5.

Minayo, M. C. S. (1992). O desafio do conhecimento: pesquisa qualitativa em saúde. São Paulo: HUCITEC/ABRASCO.

Moreira, M. A. (2012). Aprendizagem significativa: a teoria e textos complementares. São Paulo: Livraria da Física.

Nascimento, K. A\& Silva, E. W. L. (2019). As principais dificuldades do estágio supervisionado no curso de licenciatura em computação e a sua relação com a formação docente. Brazilian Journal of Development. 5(12). Doi:10.34117/bjdv5n12-137

Pimenta, S. G.\& Lima, M. S. L. (2012). Estágio e docência. São Paulo: Cortez.

Pimenta, S. G. (2017). Os cursos de licenciatura em pedagogia: fragilidades na formação inicial do professor polivalente. Educação e Pesquisa, São Paulo, 43(1),15-30. Doi: 10.1590/s15179702201701152815.

Rocha, A. C.\&Pozzebon, M. C. L. (2013). Reflexões sobre a práxis: as vivências no estágio supervisionado em história. História \& Ensino, 19(1), 71-98.

Sebastião, L. L.\& Freire, E. S. (2009). A utilização de recursos materiais alternativos nas aulas de Educação Física: Um estudo de caso. Pensar a Prática, 12(3). Doi: 10.5216/rpp.v12i3.6766. 
Silva Junior, A. P. (2016). Configurações e relações estabelecidas no Estágio Curricular Supervisionado na formação inicial de professores de Educação Física. Tese de Doutorado, Programa de Pós Graduação em Educação Física, Departamento de Educação Física, Universidade Estadual de Maringá. Maringá, Brasil.

Silva, M.\& Ferreira, A.\&Jesus, I.\&Alencar, G.\& Araújo, V. (2019). Consciência fonológica: articulação entre teoria e prática por meio do programa residência pedagógica. Trabalho apresentado no III Encontro das Licenciaturas Região Sul, Curitiba, Brasil.

Soler, R. (2003). Educação Física escolar. Rio de Janeiro: Sprint.

Souza, A. G.\& Freire, E. S. (2008). Planejamento participativo e Educação Física: envolvimento e opinião dos alunos do Ensino Médio. Revista Mackenzie de Educação Física e Esporte, 7(3).

Tardif, M. (2002). Saberes docentes e formação profissional. Petrópolis, RJ: Vozes.

Tavares, A., Santos, F., \& SANTOS, L. (2020). Políticas Públicas, educação escolar e educação profissional: apontamentos sobre as reformas a partir de 1990. Holos, 2, 1-11. doi:https://doi.org/10.15628/holos.2020.7817.

Teixeira, A. (1971). Educação não é privilégio. São Paulo: Companhia Editora Nacional.

Zeichner, K. (2010). Repensando as conexões entre a formação na universidade e as experiências de campo na formação de professores em faculdades e universidades. Educação, 35(3), 479-504. Doi: $10.5902 / 198464442357$. 